\title{
Research on incentives and constraints of agent construction projects
}

\author{
Dongjie Ye ${ }^{1}$, Lvming Wang ${ }^{2}$
}

${ }^{1}$ Zhejiang Tongzhou Construction Management Ltd., Zhejiang, China

${ }^{2}$ Cixi Construction and Installation Engineering Quality Supervision Station, Zhejiang, China

Keywords: project construction; model; incentive mechanism.

\begin{abstract}
In cognizance of incentive mechanism, this article analysis from interior incentive and exterior incentive of agent construction. The interior incentive, Mainly inducted the principal-agent model, it assumed that the agency the one of "social" which break the traditional for the purpose of maximize the earnings expectations between the government investor and agent construction units; The exterior incentive, this article introduction of the reputation model's, analysis that the effect balanced conditions and the impact of factors of reputation, Proved that under certain conditions inducted the reputation incentive model's will be have a stronger. Provide real significance for the further development of agent construction.
\end{abstract}

\section{Introduction}

Agent Construction System, as a new-type mode arising in the field of national construction currently, becomes one of the highlights in the fields of infrastructure construction, owing to its unique superiority. The gradually improving mode of Agent Construction System has been adopted by an increasingly large number of projects. The marketization operation mode of Agent Construction System has considerably improved the level of project management, and the accumulating experience of operation has provided a crucial guarantee for the spread in a wider scope.

The agent construction projects is a new things that adapt to change the development of the times, it will be an inevitable trend for the investment in the future, and it's also the universal practice in developed countries at present. As an innovative management system, the agent construction have been generally applied in all provinces after the State Department brought forward agent construction for the reform of investment system in domestic. It has acquired satisfactory achievements through the project management practice in the past four years, especially played an important restraint role in the three-excess phenomenon of Government project. The agent construction projects is an exploratory work. Although the basic idea is correct, the operation encountered a lot of problems, such as the legal status of agent construction units(relevant government functional departments give agent construction units a tumble), involved tripartite responsibility (government investor, agent construction units, user) division in construction process of the agent construction project, designate the nature of agent construction units (that is, choose what type and quality agent construction units), agent construction units should bear the legal responsibility and liability for compensation, agent cost and so on. The main reason of these problems is that agent construction's incentive and restraint mechanism is not consummate. Under such circumstances, the problem is that how to establish a scientific incentive and restrictive mechanism to guide the strong comprehensive strength of the project management company to enter the market of agent construction is deserve to discuss.

\section{The Classification of construction project}

Different breakthrough points form different classification methods and categories. Fems in accordance with the component characteristics of construction project divided it into business-cycle type, agent construction object type and single-objective type ${ }^{[1]}$. Pellegnnelli, whose classification was the same as that of Fems, divided construction project into portfolio type, goal-oriented type and heartbeat type. Gray divided construction project into loose type, strong type and open type in 
accordance with the relation between the projects composing construction project. Reiss, according to the cognition degree of organizations on construction project, divided it into operation type, middle type and inexperienced type ${ }^{[2-3]}$. This paper from the standpoint of the function setting and the overall objective to be achieved of organizations on construction project management divides construction project into interior incentive tactic type and strategy type ${ }^{[4]}$. Interior incentive tactic type construction project includes resource combination type and maintenance-improvement type, while exterior incentive strategy-type construction project includes agent construction object orientation type and megaproject type, as shown in Figure 1.

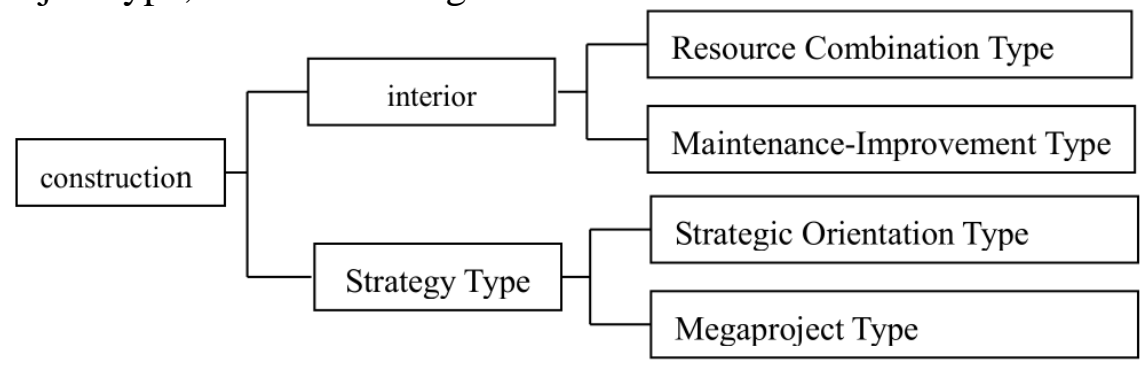

Fig. 1 Classification of construction project

\section{Tactical construction project}

Interior incentive tactic type construction project refers to coordinating and managing construction project under the guidance of corporate strategy for some characteristics of a set of projects to achieve local optimization and increase the profits of organizations.

(1) Resource Combination Type

Due to the stimulation from external environment, enterprises focus on soliciting projects continually, taking into less consideration their resource capability. When the resource demand of all projects exceeds the total resources that enterprises can acquire, it is inevitable that the operation of partial projects goes wrong. Under the environment of resource strain, the single project managers within system instinctively strive for more resources on their own interests to guarantee the achievement of project objective, which aggravates the lack of enterprise resources, the confusion of distribution and the inefficiency of use, ultimately reducing enterprises' overall interests ${ }^{[5]}$.

The resource combination type of construction project aims at the efficient use of resources. The projects in the combination both can be the similar ones with strong relevance and can be the different, relatively independent ones, and both need the same limited resources. This type of construction project management has little influence over the original linear relation of organizations, and focuses on coordinating customers, project managers and functional managers as well as the relation between them ${ }^{[6]}$. However, this type of construction project span is short due to its component nature, therefore, if new combination can bring larger benefits, this means that the life of original construction project ends and new life starts.

(2) Maintenance-Improvement Type.

The net profit rate of domestic construction enterprises has been in a low level, averagely less than 4\%. Although the causes include imperfect construction market, unsound tender procedure, bid procedure and laws, the extensive management within the enterprises is a unavoidable problem. Therefore, enterprises need to continually improve their internal management and adapt to market environment to enhance their competitive power and profitability.

Establishing the maintenance-improvement type of construction project aims at improving the existing system, optimizing the key business and procedure, and increasing or promoting the system function to acquire the increment benefits. When construction project management framework doesn't exist, the functional department is usually responsible for the tasks above, but this approach lacks integrity and continuity, which influences the effectiveness of implementation. The maintenance-improvement type of construction project, which integrates the various needs of enterprises, projects and customers and accepts or refuses these needs from the angle of enterprises as a whole, summarizes the needs accepted as a clear definition with internal consistency, and realizes 
these needs through multiple projects based on feasible technique and effective operation. This type of construction project can be perpetual, and its implementation process can be gradual, thus enterprises can enhance and strengthen their system capacities under the balanced state of change and stability.

\section{Organizational Structure}

In accordance with the different positions and functions of construction project management office in the organizational structure of construction project management, this paper divides the organizational structure into interior incentive tactic type and strategy type.

Organizational structure of interior interior incentive tactic type construction project management

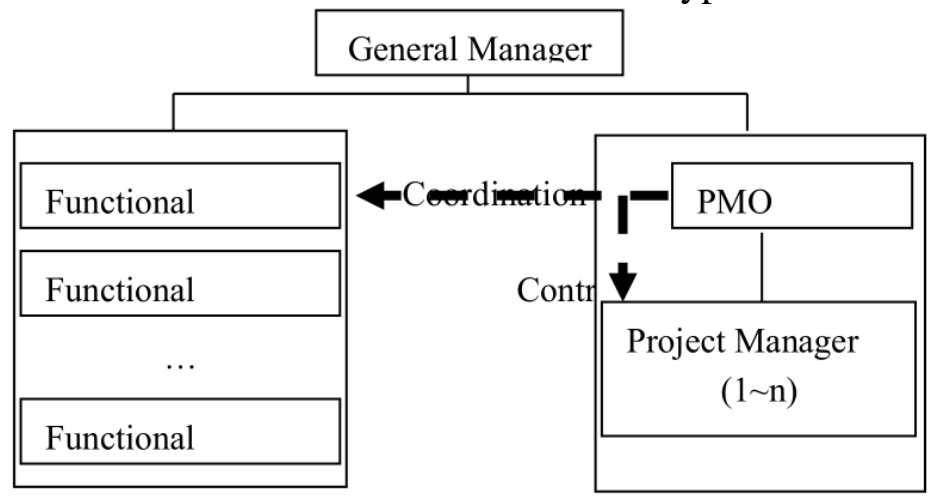

Fig. 2 Organizational structure chart of interior incentive interior incentive tactic type agent construction object

Taking the characteristics of interior incentive tactic type construction project management into consideration, such as clear objectives, expected earnings easy to be measured and appraised and small adjustment range in response to changes, and comprehensively weighting its organizational level and span, its organizational structure is shown in Figure 2. From the lateral section, the construction project management office is responsible for coordinating with other functional departments on affairs conductive to successful construction project management and reporting to general manager on its work. From the longitudinal section, the office is responsible for directly managing its projects, optimizing the distribution of resources and mediating the contradictions between projects to provide supports for the successful implementation of projects. Project manager directly reports its work to the construction project management office which is in charge of the successful implementation of project.

Organizational structure of exterior incentive strategy-type agent construction object management

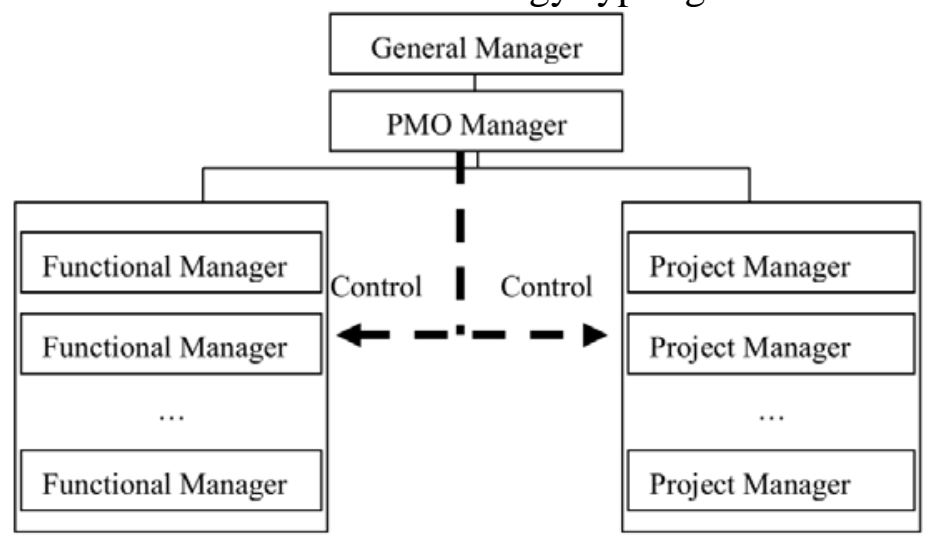

Fig.3 Organizational structure chart of exterior incentive strategy-type agent construction object

In exterior incentive strategy-type agent construction object management, the strategic objectives of organizations are often obscure and incomplete, their implementation methods are also changeable with environmental changes, their expected earnings are difficult to be forecast, and they need control and certain flexibility. Under such a circumstance, in order to avoid the confusion of responsibilities caused by the decentralization of power and too many requirements on managers and enhance the 
effectiveness and efficiency of agent construction object implementation, it is necessary to set up an integrated and powerful centralized control unit to complete the four main tasks including coordination, control, support and appraisal. The organizational structure of exterior incentive strategy-type agent construction object management is shown in Figure 3. The agent construction object management office lays out the strategic objectives comprehensively to determine the implementation methods and action tactics. From the lateral section, the office can mobilize resources of each department, and allocate and optimize these resources according to the priority of projects. From the longitudinal section, the office is in charge of dividing the objectives, defining the priority, analyzing the constrained relation and interface, and launching and ending the projects. Moreover, the office also needs to monitor and appraise the agent construction object dynamically during the implementation, bring the implementation of agent construction object into correspondence with the objectives throughout, and analyze and evaluate the earnings received.

\section{Conclusion}

Traditional agent construction object management focuses on the environmental analysis, the establishment of organizational capability and the strategy formulation at the corporate level, lacking studies on strategy implementation, especially on how to organize strategy through project implementation. Agent construction object management focuses on directivity while project management focuses on implementation, and the separation between strategy level and implementation level is always an important problem that project organizations face. This problem becomes more pressing due to rapid environmental changes, and the interaction between the external environmental changes caused by customers, competitors, shareholders and other stakeholders and the internal environmental changes caused by adjustment of organizational development strategy, transfer of organizational structure and staff and change of corporate culture and management style poses a huge challenge to the implementation, survival and development of organizational strategy.To restraint mechanism, this article started with interior restraint and exterior restraint separately. Analysised the issue of rent-seeking, the problem of responsibility of agent construction, communication mechanism, and agent System's legal environment issues and so on.

\section{Reference}

[1] Qinghua He, Lan Luo, Yi Hu, Albert P.C. Chan, Measuring the complexity of mega construction projects in China - A fuzzy analytic network process analysis J. International Journal of Project Management, 2014.

[2] Jeroen Rijke, Sebastiaan van Herk, Chris Zevenbergen, Adaptive construction project management through a balanced performance/strategy oriented focus J. International Journal of Project Management. 32(2014)1197-1209.

[3] Mark Lycett, Andreas Rassau, John Danson, construction project management: a critical review J. International Journal of Project Management. 22(2004)289-299.

[4] David Partington, Sergio Pellegrinelli, Malcolm Young, Attributes and levels of construction project management competence: an interpretive study J. International Journal of Project Management. 23(2005)87-95.

[5] APM, The Association for Project Management Body of Knowledge , APM: High Wycombe, UK, 2000.

[6] OGC, Managing successful construction project s, UK: Office of Government Commerce OGC, The Stationery Office, 2007. 